\title{
EMANCIPAÇÕES DISTRITAIS NO BRASIL DURANTE A DÉCADA \\ DE 1990 E O GRAU DE SUCESSO MEDIANTE ANÁLISE DO IDH
}

\author{
Marcos Antônio Nunes*
}

\section{Resumo}

A Constituição Federal de 1988, ao conceder maior autonomia às unidades federativas sobre a temática das emancipações, contribuiu para que ocorresse no país novo surto emancipacionista. No decorrer da década de 1990 foram criados mais de mil municípios. Vis-à-vis as vantagens e desvantagens das emancipações, a questão que se coloca é: de que maneira pode-se medir o grau de sucesso dessas emancipações distritais no período? Neste trabalho utilizou-se o Índice de Desenvolvimento Humano (IDH), por ser um indicador sintético que congrega as dimensões educação, longevidade e renda, e assim avaliar, através do método estatístico regressão logística, o quanto os municípios recém-criados evoluíram em relação aos demais.

Palavras-chave:Métodos Quantitativos. IDH. Emancipações. Municípios brasileiros.

\footnotetext{
*Doutorando em Geografia, Departamento de Geografia do Instituto de Geociências da UFMG; pesquisador do Instituto de Geociências Aplicadas (SECTES - Governo de Minas Gerais); marcos.geoman@gmail.com 


\section{INTRODUÇÃO}

De acordo com o Projeto de Lei Complementar 416/2008, o Brasil poderá somar aos seus 5.570 municípios cerca de 190 outros, se os distritos pleiteantes reunirem as condições exigidas no projeto ${ }^{1}$. Até dezembro de 2012 o país contava com 5.565 municípios, contudo, após aconclusão de processos judiciais, o Brasil passou a contar com mais 5 municípios a partir de $1^{\circ}$ dejaneiro de 2013.

Pescaria Brava, Balneário Rincão, ambos em Santa Catarina, Mojuí dos Campos (PA), Pinto Bandeira (RS) e Paraíso das Águas (MS) tornaram-se municípios em 2013, apesar de que aconsulta às respectivas populações envolvidas ter ocorrido há quase 15 anos. O processo foiconcluído recentemente pelo Judiciário, porque, até 1996, os critérios para a emancipação dedistritos eram estabelecidos pelas assembleias legislativas. Depois, a Emenda Constitucional15/1996 estabeleceu que as exigências devessem constar numa legislação federal, destarte aaprovação para a emancipação distrital passe ainda pelas assembleias estaduais. $\mathrm{O}$ projeto delei que deveria criar estes critérios, até então, não tinha sido aprovado pelo Congresso. Comoos plebiscitos aconteceram depois desse período, acabou gerando uma queda de braçonaJustiça. Outra emenda validou os atos de criação, fusão, incorporação e desmembramento de municípios criados até 31 de dezembro de 2006 (CASTRO, 2013).

No entanto, o que demonstra consenso entre políticos e segmentos da sociedade écomo esses municípios se sustentarão, e se há viabilidade econômica e financeira de modoque não deixem o ônus para os municípios que lhes deram origem. Os distritos que seemanciparam durante a década de 1990 podem servir de parâmetro para uma análise davalidade dessas emancipações.

Assim, esta pesquisa pretende avaliar o grau de sucesso obtido pelo conjunto dosmunicípios brasileiros criados na década de 1990, mediante análise de desempenho do IDH doperíodo posterior, para as diferentes categorias: municípios recém-criados, municípios-mãe emunicípios neutros $^{2}$. A hipótese que instiga a pesquisa é que: os municípios recémcriadossurgiram sem dívidas administrativas, portanto aptos a contraírem os primeiros empréstimos paraa construção de infraestrutura para o funcionamento da administração

\footnotetext{
${ }^{1}$ Estudo realizado pela União Brasileira em Defesa da Criação de Novos Municípios (UBDCNM) revela os estados brasileiros que têm mais distritos em condições de se emanciparem. Ver (ANEXO 1).

${ }^{2}$ Os termos utilizados nesta pesquisa se equivalem: "município-mãe" ou "remanescente"; "município-filho" ou

"recém-criado"; e "município neutro" ou "não desmembrado", ou ainda "que não sofreu alteração". 
pública municipal, edisponibilizar serviços essenciais à população - uma das causas que estimulam as emancipações.Por seu turno, os municípios-mãe, ou remanescentes, reduziram despesas de custeio com asemancipações, mas ficaram com o ônus da dívida pública municipal e eventuais gastos realizadosno(s) ex-distrito(s). Assim, espera-se que o ritmo de crescimento do IDH para os municípiosrecém-criados seja superior ao de outras categorias.

Antes, contudo, de descrever a metodologia utilizada no trabalho, a próxima seção resgataaspectos históricos do municipalismo brasileiro, em que a criação de municípios seguiutrajetórias distintas. Os períodos de nossa história e as formas de governo refletiram em boamedida para a definição de políticas centralizadoras, contidas nas diferentes constituiçõesfederais. Como será visto, essas políticas pouco contribuíram para tornar os municípiosbrasileiros autônomos e menos dependentes do governo federal.

\section{1- MUNICIPALISMO BRASILEIRO E AS CONSTITUIÇÕES FEDERAIS ${ }^{3}$}

No Brasil, o município precedeu ao próprio estado ou unidade da federação.Alguns fatores podem explicar a vitalidade alcançada pelas instituições municipais, pelo menos no período colonial: a distância da metrópole, as preocupações da Coroa de Portugal com as Índias e a guerra da Espanha, e a própria vastidão do território da Colônia.

O municipalismo brasileiro tem sua gênese no modelo da República Romana, que o impôs às regiões conquistadas, como a Península Ibérica, de onde, naturalmente, chegou ao Brasil Colônia. As Ordenações Afonsinas, Manuelinas e Filipinas, que, regendo Portugal, também regeram o Brasil desde o seu descobrimento até a independência, e reproduziram omodelo municipal lusitano em nosso país, com as mesmas atribuições políticas, administrativas e judiciais. Os municípios tinham um presidente, três vereadores, um procurador, dois almotacés ${ }^{4}$, um escrivão, um juiz de fora vitalício e dois juízes comuns, eleitos com os vereadores, sendo que no poder político dos vereadores e no poder econômicodos grandes proprietários rurais residia a força política das municipalidades.

A primeira república municipal brasileira, ou o primeiro governo local autônomo das Américas foi instalado em São Vicente, em 1532. Depois outros municípios foram instalados:Olinda (1537), Santos (1545), Salvador (1549), Santo André da Borda do Campo (1553) eRio de Janeiro (1567).

\footnotetext{
${ }^{3}$ Adaptado de Nunes (2001). "Breves notas sobre a evolução do municipalismo no Brasil”. Cap. 1, p. 5-20.

${ }^{4}$ Inspetor encarregado da aplicação exata dos pesos e medidas e da taxação dos gêneros alimentícios. 
No período colonial foram organizadas as câmaras municipais de acordo com a vontade política dos vereadores e a força econômica dos grandes proprietários. As Casas Legislativas Municipais passam a refletir os interesses locais em consonância com as aspirações populares.

Já no período imperial, a Constituição Política do Império do Brasil (25/03/1824) restringiu o exercício das funções municipais que seriam decretadas por uma lei regulamentar (CRETELLA JR., 1981, p. 41). O período imperial foi caracterizado pelo enfraquecimento da atuação das câmaras municipais, que perderam funções políticas efinanceiras. O Brasil não chegou a ter governo municipal autônomo, já que toda a evoluçãopolítica e jurídica direcionouse para as províncias. Com isto, os municípios passaram a sertutelados, perdendo a função judicante, que lhes dera prestígio e poder no período colonial $1^{5}$.De fato, pode-se dizer que esta fase veio congelar o avanço das instituições municipais, gerando um indesejado imobilismo em seu processo evolutivo.

Já no Brasil República, a Constituição de 1891 fez retornar a autonomia municipal, apoiada nas respectivas constituições estaduais e leis orgânicas municipais. $\mathrm{Na}$ vigência dessa constituição, todavia, os municípios não gozaram de autonomia real, em face dapolítica centralizadora do governo federal. Arbitrariedades cometidas pelos estados para com os municípios levaram a União a realizar uma reforma constitucional em 1926,facultando a intervenção direta nos estados para proteger a autonomia municipal.

Durante a Era Vargas, o Brasil retorna novamente ao sistema centralizado de administração, ao extinguir todos os poderes legislativos, inclusive os municipais. Entretanto, os fatos políticos dos anos 1930-1934 levaram Getúlio Vargas a convocar a Assembleia Constituinte, restabelecendo, assim, na Constituição de 1934, a autonomia dosmunicípios. $\mathrm{Na}$ ocasião, os municípios foram dotados de mais recursos financeiros, pois seria retirada dos estados uma parcela dos seus impostos.

Com o golpe de estado de 1937, que marcaria a transição para o Estado Novo, o Brasil retoma novamente o modelo centralizador, sendo que desta feita os prefeitos seriamnomeados pelos governadores, e não mais eleitos.

$\mathrm{Na}$ Constituição de 1946 renasce o municipalismo no Brasil, caracterizado por sua autonomia política, administrativa e financeira. A União transfere parte de seus tributos edos estados para os municípios. A partir dessa época, surgiram municípios em todos os estados.

\footnotetext{
${ }^{5} \mathrm{Na}$ atualidade, os municípios brasileiros são constituídos pelos poderes Executivo e Legislativo. O Judiciário está presente nos níveis estadual e federal. 
A TABELA 1 mostra a evolução do número de municípios brasileiros. Até 1940 o Brasil contava com 1.574 municípios, número que se elevou para 1.889 em 1950. Nota-seque o incremento nesta década foi de 46,4\%, sob os efeitos da Constituição de 1946. As décadas subsequentes, 1950 e 1960, registraram as maiores taxas de crescimento do númerode municípios.

O surto emancipacionista desse período deve-se à possibilidade de os municípios arrecadarem recursos federais por conta das cotas do Imposto de Renda que a União deveriarestituir às unidades em que fosse arrecadado. Conforme salientou Carvalho (1985, p. 5), "édese prever que boa parte desses novos municípios tenha sido emancipada precocemente,sem efetivas condições de sobrevivência, sendo, por conseguinte inviáveis".

Tabela 1- Evolução do número de municípios no Brasil

\begin{tabular}{c|c|c}
\hline ANO & $\begin{array}{c}\text { NÚMERO DE } \\
\text { MUNICIPIOS }\end{array}$ & $\begin{array}{c}\text { TAXA DE CRESCIMENTO } \\
\text { ENTRE OS PERIODOS (\%) }\end{array}$ \\
\hline 1940 & 1.574 & - \\
\hline 1950 & 1.889 & 20,0 \\
\hline 1960 & 2.766 & 46,4 \\
\hline 1970 & 3.952 & 42,9 \\
\hline 1980 & 3.991 & 1,0 \\
\hline 1991 & 4.491 & 12,5 \\
\hline 2000 & 5.507 & 22,6 \\
\hline 2010 & 5.565 & 1,1 \\
\hline
\end{tabular}

FONTE: Adaptado de Bremaeker (1991); dados de 2000 e 2010 são do IBGE.

A Constituição de 1967, durante o Governo Militar, apesar de ter mantido o princípio da autonomia municipal, limitou a criação de municípios e estabeleceu novos critérios paranão cometer os excessos verificados após a Constituição de 1946. O que explica o baixo crescimento relativo, 1\%, do crescimento das emancipações na década de 1970.

Por fim, a Constituição Federal de 1988 restabeleceu a autonomia dos municípios eassegurou-lhes a transferência de outros impostos. Nesta Constituição, reconheceram-se o poder de auto-organização e a reafirmação de um governo próprio, mediante o voto popular.

Durante a década de 1990, o Brasil assistiu a um grande surto de emancipaçõesdistritais, resultado de brechas deixadas pela Constituição Federal de 1988, que não estabeleceu regras e limites sobre esse tema para as assembleias estaduais. $O$ maior reflexo das emancipações 
ocorreu na década de 1990, quando o país registrou o surgimento de mais de mil municípios crescimento de 22,6\% em relação a 1991.

A resposta do governo federal só viria em 1996, com a aprovação da EmendaConstitucional $n^{\circ} 15$, que, praticamente, aniquilou qualquer possibilidade de novos surtos emancipacionistas no Brasil.

\section{1- A Emenda Constitucional $\mathrm{N}^{\circ}$ 15: novo freio}

Até 1996, a criação, a incorporação, a fusão ou o desmembramento de municípios ${ }^{6}$ eram realizados por lei estadual conforme $\int 4^{\circ}$ do art. 18 da Constituição Federal. Tendo emvista a eclosão do número de municípios no país após a promulgação da Carta Magna, ogoverno federal procurou, claramente, refrear o processo de emancipações e passou a legislarsobre o tema. O governo reagia, assim, à excessiva multiplicação de municípios, alguns semmínimas condições econômicas de funcionamento.

Dessa forma, a Emenda Constitucional 15 de 1996 deu nova redação ao art. 18 da Constituição Federal:

A criação, a incorporação, a fusão e o desmembramento de Municípios, far-se-ãopor lei estadual, dentro do período determinado por lei complementar federal, edependerão de consulta prévia, mediante plebiscito, às populações dos Municípiosenvolvidos, após divulgação dos Estudos de Viabilidade Municipal, apresentados epublicados na forma da lei (BRASIL, 1996).

A Emenda $n^{\circ} 15$ passa a restringir as emancipações com a incorporação de exigências que, até então, não eram cobradas pelas assembleias legislativas estaduais. As mudançasforam basicamente no quesito "plebiscito" e na exigência de um "Estudo de Viabilidade Municipal”.

Para Bremaeker (1996), as autoridades do Executivo federal já conheciam os reais motivos que levavam à emancipação dos municípios, quando teve início a tramitação do projeto da Emenda $n^{\circ} 15$. O estudo realizado junto aos municípios emancipados indicava ascausas de sua criação: o descaso da administração do município de origem (54,2\% dos casos); a existência de uma forte atividade econômica local (23,6\%); a grande extensão territorial do município de origem ${ }^{7}(20,8 \%)$; e o grande aumento da população local, apontado por 1,4\% dos municípios emancipados.

\footnotetext{
${ }^{6}$ Ver ANEXO 2 que contém o glossário desses termos.

${ }^{7}$ Para o ex-deputado estadual José Braga, autor do projeto de lei que deu origem às emancipações distritais emMinas Gerais na década de 1990, a divisão beneficiou tanto os antigos quanto os novos municípios. Os antigos, porque com a redução da área, tornou-se mais fácil administrar; os novos, porque alcançaram melhorias, sobretudo nas áreas sociais (NUNES, 2001). Esta pode ser outra possibilidade de pesquisa, ao incluir na 
Souza (1997) analisou os itens da Emenda sob um ponto de vista restrito à órbitajurídica, sem emitir juízo acerca das vantagens advindas com o processo de emancipações.

Para a autora, as legislações estaduais foram demasiadamente permissivas em relação ao estabelecimento de requisitos mínimos para os processos de emancipação, que são estimulados por interesses político-partidários e eleitorais. Assim, as emancipações são maisque um meio de alterar a geografia da organização político-administrativa; elas lidam, antesde tudo, com o aparato técnico que se refere às finanças do estado e sua viabilidade econômica.

Diante dos fatos, era necessária a elaboração de uma lei federal que regulamentasse os critérios para a criação, a incorporação, a fusão e o desmembramento de municípios nopaís. O projeto de lei do Senado, $n^{\circ} 98$ de 2002, sofreu alteração na Câmara dos Deputados(n ${ }^{\circ}$ $416 / 2008$ - complementar) ${ }^{8}$. Ao retornar ao Senado, o texto aprovado, de autoria dosenador Mozarildo Cavalcanti (PTB-RR), é um substitutivo com várias alterações do projeto original (NÉRI, 2013).

\section{2- Projeto de Lei do Senado $\mathrm{N}^{\circ}$ 98/2002 - Abertura com cautela}

A pressão contrária à Emenda Constitucional $n^{0} 15$ se materializou quando as assembleias legislativas de todo país acumularam protocolos de 800 pedidos de emancipações distritais. Desde1996 que as assembleias estaduais, os municípios e distritos interessados esperam por umadefinição. As assembleias estão sendo assediadas (pelos distritos) e não podem fazer nada sem um respaldo federal. E agora a pressão chegou a nós, conta o vice-líder do PMDB/CE naCâmara, Mauro Benevides (SOUTO, 2011).

Casos extremos ocorreram no início de 2013 no norte do país, no distrito de Extrema, em Rondônia, quando manifestantes favoráveis à emancipação do distrito fecharam a BR-364. Houve repressão militar para conter as manifestações (EMANCIPAÇÃO..., 2013). Estefato contribuiu para que o senador Valdir Raupp (PMDB/RO) fosse o relator do Projeto deLei Complementar (PLP 416/2008), que trata, entre outros, das emancipações distritais.

No dia 16 de outubro de 2013, o Senado brasileiro aprovou novas regras para fusão, criação e desmembramento de municípios. Com a aprovação do Projeto de Lei Complementar 98/2002, 188 distritos passam a ter condição de se emancipar e virar municípios. O texto

modelagem as variáveis que contemplem a extensão territorial e a distância das sedes municipais às vilas dos distritos pleiteantes à emancipação.

${ }^{8}$ Sobre as alterações propostas pela Câmara dos Deputados em relação ao Projeto de Lei do Senado no 98 de2002, ver quadro comparativo em: <http://www.senado.gov.br/atividade/materia/detalhes.asp?p_cod_mate=113088>. Acesso em: 12 nov. 2013. 
aprovado seguirá para sanção da presidente Dilma Rousseff. Em todosos casos, a criação, a incorporação, a fusão e o desmembramento de municípios dependerãoda elaboração do Estudo de Viabilidade Municipal (EVM) e de consulta prévia, mediante plebiscito, às populações envolvidas (SENADO..., 2013).

O retorno do Estudo de Viabilidade Municipal, com novos critérios, demonstra que o governo federal está atento às emancipações de caráter político-eleitoral. Em relação ao processo anterior, o refrear mostra que o caminho para as emancipações tornou-se mais difícil, sobretudo se o Art. 22, do projeto de lei em questão, não for vetado:

Art. 22. Os Municípios que forem criados ou tiverem suas áreas territoriaisampliadas em função de desmembramento indenizarão os respectivos Municípiosde origem pela cota-parte das dívidas vencíveis após a redivisão territorial, contraídas para execução de obras e serviços que tenham beneficiado os territóriosque foram desmembrados ou transformados em novos Municípios (BRASIL, 2013).

Como bem advertiu Maria Amarante P. Baracho (2000, p. 61-62), ao estudar os impactos das emancipações na arrecadação de ICMS dos municípios mineiros, neste processo é essencialconsiderar como pressuposto fundamental a não-destruição das bases econômicas do município aser desmembrado. Este deve ter aproximadamente a mesma densidade de população e receita,impostos e transferências que o município que lhe deu origem. Estas considerações são importantes para que as duas partes não sejam punidas com o processo emancipatório e quepossam garantir um serviço público de qualidade à população.

As ponderações feitas pelos senadores, sobre os critérios adotados na legislação emanálise, soam como positivas. Primeiro, pelo fato de o texto exigir um limite mínimo populacional, que irá variar em conformidade com as cinco regiões oficiais do IBGE. Assim,neste quesito, o rigor foi maior para os distritos localizados nas regiões Sudeste e Sul. Segundo, a necessidade de um estudo sobre a viabilidade econômica e financeira de cada município a ser criado. O fator distância ${ }^{10}$ entre as sedes municipais e distritais foi lembradopelo senador Blairo Maggi (PR-MT), que salientou a importância das emancipações para ocaso dos distritos mato-grossenses que distam mais de $400 \mathrm{~km}$ das sedes municipais

\footnotetext{
${ }^{9}$ Após o encerramento desta pesquisa, na quarta-feira, dia 13 de novembro, a presidente Dilma Houssef vetou o projeto aprovado no Senado Federal que trata das emancipações. A presidente alegou aumento das despesas sem o crescimento de receitas equivalentes (DILMA..., 2013).

${ }^{10} \mathrm{Na}$ região Norte do Brasil, onde estão os maiores municípios em extensão, como é o caso de Altamira (PA), écomum a distância de centenas de quilômetros entre as sedes municipais e as vilas. Esta variável merece ser considerada e analisada em uma próxima pesquisa.
} 
(PLENÁRIO, 2013). Os critérios ${ }^{11}$ poderiam sofrer vetos parciais, mas, como visto, a presidente Dilma optou pelo veto total do projeto.

Os fatores que contribuem para a formação de municípios são diversos e não se limitam a fatores políticos e socioeconômicos relativos à localidade ou região em questão. Mesquita (s.d.) realizou abordagem que ultrapassa as escalas política e econômica do local oudo regional, ao considerar que as transformações espaciais em curso, expressas pelas fragmentações territoriais, são determinadas pelas mudanças na política e na economia emnível nacional e mundial.

Uma explicação para esse surto crescente de emancipações que ultrapasse a meradescrição de uma divisão administrativa conduz â hipótese de que as transformações econômicas e políticas nacionais e mundiais atuam pela modernização (cuja iniciativa cabe ao EstadoNação), em sua faculdade de homogeneizar a produção e o consumo. Entretanto, dada à diferenciação espacial - em seus aspectos físicos, sociais, políticos e econômicos —-, essa homogeneização nunca se realiza completamente, permitindo a existência de espaços diferenciados

em escalas geográficas distintas. As fragmentações e integrações territoriais são expressões visíveis desse fenômeno (MESQUITA, s.d., p. 170).

Na mesma perspectiva, Röckert (1984) considera importante compreender osprocessos espaciais e o comportamento do capitalismo urbano industrial e financeiro nos países em desenvolvimento, e sua penetração no espaço nacional. Ocorre, assim, uma articulação entre centros de interesses nacionais e mundiais. Nesta ótica, os interesses das sociedades localizadas mais no interior, nos espaços periféricos, em última escala, no "fim dahierarquia urbana" e no campo, passam a ser objetos de atenção. A emancipação distrital é,eminentemente, a concretização de interesses locais de comando e de integração aos interesses maiores do capitalismo moderno.

Em suma, o processo de criação de municípios deve seguir critérios que possamassegurar uma real inserção das populações locais nos debates e nas decisões governamentais, em termos regionais e/ou nacional. Caso contrário, o resultado a ser alcançado será o inverso do esperado: enfraquecimento dos municípios, perda de autonomia,e consequente afastamento do Estado na resolução dos problemas e necessidades das comunidades locais (NUNES, 2001).

\footnotetext{
${ }^{11}$ Ver as principais etapas para a criação de municípios no ANEXO 3. 
A avaliação do grau de sucesso desses municípios pode ser realizada mediante a modelagem de dados que expliquem o comportamento das categorias de municípios. A próxima seção descreve as etapas para essa mensuração.

\section{2- METODOLOGIA}

Para avaliar o grau de sucesso obtido pelo conjunto dos municípios brasileiros que foram criados na década de 1990, a pesquisa utilizou o Índice de Desenvolvimento HumanoMunicipal (IDH-M), por ser um indicador sintético que congrega as dimensões educação, longevidade e renda.

O IDH foi formulado por MahbubulHaq com a colaboração do economista indiano Amartya Sen. É uma medida sintética que resume o progresso alcançado pelo conjunto populacional, em longo prazo. Seu principal objetivo é oferecer uma alternativa a outro indicador, não menos importante, que é o Produto Interno Bruto (PIB) per capita ${ }^{12}$, que considera apenas a dimensão econômica do desenvolvimento. O enfoque nas liberdades humanas contrasta com visões mais restritas de desenvolvimento, como as que identificamdesenvolvimento com crescimento das rendas pessoais, industrialização, etc (SEN, 2010). Embora seja um indicador sintético, O IDH não abrange nem esgota todos os aspectos dodesenvolvimento.

No primeiro momento, necessitou associar dois bancos de dados distintos pelo código do IBGE. O primeiro banco de dados, da Fundação João Pinheiro, contém os códigos municipais com as respectivas categorias ("filho", "mãe", e "não desmembrado"). Por seuturno, o segundo banco de dados contém tanto os códigos dos municípios quanto os valoresdos IDHs para os períodos censitários 1991, 2000 e 2010. O “n”, total de municípios foradefinido pelo primeiro banco de dados, não obstante o segundo contar com todos os municípios brasileiros até 2010.

\footnotetext{
${ }^{12} \mathrm{O}$ PIB per capita tem a vantagem de ponderar sobre as variações do tamanho populacional, e representar arenda média da população. Aí reside uma limitação do indicador, por não revelar o nível de desigualdade de renda de uma sociedade, ou seja, ocultar a divergência de renda entre pobres e ricos, o que reflete no desvio padrão. Ainda assim, ele é considerado importante indicador de qualidade de vida, uma vez que o seu crescimento reflete diretamente na geração de riqueza.
} 
Assim, o total de municípios brasileiros analisados foi de 5.560 - o que representa mais de $99 \%$ dos municípios brasileiros. Entretanto, ao "rodar" os dados, o "n" caiu para $5.557^{13}$, o que ainda não compromete a sua validade.

Eles foram agrupados em três categorias: "filho", "mãe” e "neutro". Os municípios filhosão aqueles recém-criados, na década de 1990, em conformidade com o primeiro banco de dados. Os municípios-mãe são os que deram origem aos primeiros, e os municípiosneutroaqueles que não foram desmembrados.

No segundo momento, foram feitos testes com o modelo de regressão logística com as variáveis dependentes (IDH e PIB per capita). Utilizou-se o software SPSS ${ }^{14}$. Os testes efetuados com a variável dependente (IDH) mostraram-se positivos e bem ajustados à realidade do fenômeno das emancipações. Por sua vez, quando realizou os testes para a variável dependente PIB per capita, os resultados não foram satisfatórios.

A regressão logística é uma técnica estatística que visa realizar a predição de valores obtidos por uma variável categórica a partir de uma série de variáveis explicativas contínuasou binárias. Assim diferencia-se, por exemplo, da regressão linear que é um modelo matemático que lida com variáveis contínuas.

A regressão logística é um modelo de regressão não linear, e é utilizada quando a variável resposta é qualitativa e dicotômica, ou seja, assume dois resultados possíveis, do tipode evento Bernoulli.

Enquanto na regressão linear temos o seguinte modelo:

$$
Y=a+\beta_{1} x_{1}+\beta_{2} x_{2}+\ldots \beta_{n} x_{n}+\varepsilon
$$

Neste caso, a variável “y” é de natureza contínua e segue uma distribuição normal. Omodelo matemático visa predizer o valor médio que " $\mathrm{y}$ " assume a partir dos valores assumidos pelas suas variáveis explanatórias.

Por seu turno, e se a variável for dicotômica, com dois resultados possíveis? Oumelhor, se assumir a condição de "positivo" ou "negativo", “sim” ou “não”, “1” ou "0”? Neste caso, do ponto de vista estatístico " 1 " significa sucesso na ocorrência do evento, e "0" representa que o evento fracassou. Pondera-se que a média dessa variável dicotômica "y" é designada "p", sendo

\footnotetext{
${ }^{13}$ Está disponível no mercado brasileiro o software SPSS MissingValues. Assim, torna-se possível, entre outros, substituir valores perdidos por estimativas. Disponível em: <http://www03.ibm.com/software/products/pt/spss-missing-values>. Acesso em: 14 nov. 2013.

${ }^{14}$ StatisticalPackage for the Social Sciences, ou "Pacote Estatístico para as Ciências Sociais".
} 
este a proporção de vezes que a variável assume o valor "1" em um conjunto de eventos. Ou seja, quantas vezes $\mathrm{y}=1$ (sucesso).

Este modelo pode ser estendido quando a variável resposta qualitativa tiver mais que duas categorias, por exemplo, as três categorias de municípios supracitadas.

Neste caso, para estimar a probabilidade "p" associada a uma resposta dicotômica para diversos valores de uma variável explanatória, utiliza-se a técnica estatística chamada regressão logística, que segue o modelo ajustado:

$$
E(Y)=\left(1+\exp \left(-\beta^{\prime} X\right)\right)^{-1}
$$

Onde:

$$
\beta^{\prime} X=\beta 0+\beta_{1} X_{1}+\beta_{2} X_{2}+\beta_{3} X_{3}+\beta_{4} X_{4}
$$

O propósito dessa análise é verificar a força de associação entre as variáveispreditoras e a probabilidade, no caso, os municípios-filho, ter sucesso no incremento do IDH.

O sucesso de seu emprego, enquanto método de predição de variáveis categóricas estána possibilidade de modelar a probabilidade de um evento ocorrer como função de outros fatores. É um modelo linear generalizado que usa como função de ligação a função logit.

A função logística, assim permite descrever e predizer. Descreve a natureza dorelacionamento entre a resposta média em relação às variáveis regressoras, e prediz as chances de um determinado evento ocorrer.

\section{3- RESULTADOS E DISCUSSÃO}

Dos 5.567 municípios, após "rodar" os dados no SPSS, contabilizou-se 3.582 da categoria "neutros", 906 da categoria “mães" e 1.069 do tipo "filhos", conforme mostra oQUADRO 1.

Pode-se observar que a categoria "Neutros" corresponde à maioria absoluta dos municípios, com 64,5\%. Esses municípios não sofreram nenhuma fragmentação territorialdurante o surto emancipacionista dos anos 1990. Em segundo lugar, a categoria "Filhos", representa 19,2\% dos casos - ligeiramente superior ao tipo "Mães", com 16,3\%. Isso sugereque ocorreram, em média, 1,18 emancipações por município. Ou seja, na maioria dos 
municípios ocorreu apenas a emancipação de um distrito. É um número elevado, aoconsiderar o intervalo de uma década ${ }^{15}$. Os valores seguintes irão refletir a proporcionalidade dimensional das categorias, exceto o IDH.

Quadro 1- Dados sintéticos da área, população, PIB, PIB per capita, IDH e sua taxa de crescimento (2000-2010), segundo as categorias dos municípios brasileiros.

\begin{tabular}{|c|c|c|c|c|c|c|c|c|c|}
\hline CATEG. & $\mathbf{N}$ & $\begin{array}{c}\text { Freq. } \\
\text { Relat. } \\
\%\end{array}$ & $\begin{array}{c}\text { Área Total } \\
\mathrm{Km}^{2}\end{array}$ & $\begin{array}{c}\text { Área } \\
\%\end{array}$ & $\begin{array}{c}\text { POP. TOTAL } \\
(\mathbf{2 0 1 0})\end{array}$ & $\begin{array}{c}\text { PIB 2010 } \\
\mathbf{R} \$ 1.000 \\
(\mathbf{m} \text { édia) }\end{array}$ & $\begin{array}{c}\text { IDH } \\
(\mathbf{2 0 0 0})\end{array}$ & $\begin{array}{c}\text { IDH } \\
(\mathbf{2 0 1 0})\end{array}$ & $\begin{array}{c}\text { Tx. Média } \\
\text { Anual \% } \\
\text { IDH }\end{array}$ \\
\hline Neutros & 3.582 & 64,5 & 5.097 .213 & 59,9 & 143.888 .159 & 23.969 .808 & 0,763 & 0,709 & $-0,73$ \\
\hline Mães & 906 & 16,3 & 2.127 .213 & 25,0 & 37.178 .691 & 1.985 .608 & 0,753 & 0,707 & $-0,63$ \\
\hline Filhos & 1.069 & 19,2 & 1.286 .995 & 15,1 & 9.603 .407 & 319.355 & 0,679 & 0,644 & $-0,54$ \\
\hline Total & 5.557 & 100,0 & 8.511 .422 & 100 & 190.670 .257 & 18.491 .929 & 0,757 & 0,706 & $-0,70$ \\
\hline
\end{tabular}

Fonte: Dados tabulados pelo autor.

Quanto à área total das categorias, os “neutros" ocupavam 59,9\% do território nacional, e as demais categorias 25\% (“mães") e 15,1 ("Filhos"). No período, o fracionamento territorial representou uma redução de $37,7 \%$ da área total anterior às emancipações.

A população total das categorias bem como os valores do PIB médio também sãoproporcionais, reservando à categoria "filhos" o menor valor absoluto, 9,6 milhões de habitantes e R \$319,3 milhões de PIB médio.

Por fim, o comportamento do IDH no período, variável escolhida para essa análise, mostra justamente uma inversão no comportamento. O IDH está representado em três colunas do QUADRO 1: IDH do ano 2000, IDH de 2010, e a taxa média de crescimento anual doindicador. No período, todas as categorias apresentaram queda média, no entanto, a categoria“filhos” foi a que apresentou a maior taxa média, $-0,54 \%$.

Os resultados confirmam a hipótese levantada na pesquisa, ou seja, os municípios-filho tiveram comportamento no IDH superior ao das demais categorias. Isso se confirmou quando se realizou o teste no SPSS. O Quadro 2 representa o resultado para as variáveis categóricas: Neutros, Filhos e Mães.

\footnotetext{
${ }^{15}$ Outra questão que se coloca é: em quais regiões brasileiras as emancipações foram mais freqüentes? E quaisfatores podem explicar essas diferenças regionais do fenômeno? Ao se tratar das regiões Norte e CentroOeste, onde a fragmentação territorial seria justificável pela dimensão de seus municípios, esse número médio pode ser baixo.
} 
Quadro 2- Variáveis da Equação

\begin{tabular}{|l|r|r|r|r|r|r|}
\hline \multicolumn{1}{|c|}{ Variáveis } & \multicolumn{1}{c|}{ B } & \multicolumn{1}{c|}{ S.E. } & Wald & \multicolumn{1}{c|}{ df } & \multicolumn{1}{c|}{ Sig. } & Exp(B) \\
\hline NEUTROS & $-2,706$ & 1,226 & 4,875 & 1 &, 027 &, 067 \\
FILHOS & $-2,114$ & 1,227 & 2,967 & 1 &, 085 &, 121 \\
MÃES & $-2,612$ & 1,229 & 4,517 & 1 &, 034 &, 073 \\
Constant &, 693 & 1,225 &, 320 & 1 &, 571 & 2,000 \\
\hline
\end{tabular}

Nota-se que a significância (Sig.) apresentou valores inferiores a 0,05, exceto para avariável "Filhos", que registrou 0,085 - valor que não é discrepante - o que permite aceitar o modelo. A coluna $\operatorname{Exp}(B)$ representa o efeito ou o grau de sucesso das categorias. A cada unidade de variação em Xi (Neutros, Filhos e Mães) aumenta Beta vezes a chance de Y obter sucesso.

Assim, para o conjunto dos municípios brasileiros que não passaram poremancipações (Neutros) no período, a chance do IDH sofrer incremento é de apenas 6,7\%. Enquanto para a categoria "Filhos" a chance é de 12,1\%, praticamente o dobro da primeira categoria. Por fim, para a categoria "Mães" a chance é de $7.3 \%$. No entanto, os valores ainda são relativamente baixos, o que pode sugerir outras hipóteses.

\section{CONSIDERAÇÕES FINAIS E RECOMENDAÇÕES}

A fragmentação territorial através da criação de municípios continuará no Brasil, mesmo que em ritmo menor, ao considerar o vasto território ainda em processo de ocupaçãohumana, notadamente nas regiões Norte e Centro-Oeste. Também devido à grande extensãoterritorial de muitos municípios brasileiros, que, por si só, torna-se um empecilho à administração pública municipal.

A compreensão desse fenômeno, de natureza interdisciplinar, merece uma análise que não deve se limitar ao espaço regional e mesmo nacional. Sugere-se, portanto, para os 
quepalmilharem neste tema, considerar as diferentes escalas de articulação, inclusive as espaciais- que ultrapassa os objetivos desse trabalho.

A pesquisa apontou que o grau de sucesso - termo cunhado para descrever o percentual de chance tem as categorias de municípios em incrementar o seu IDH apresentado pelos municípios recém-criados está aquém do que inicialmente se afirmou comopressuposto. Ainda assim, os resultados sindicam que a chance de os municípios recémcriadosincrementarem o seu IDH em relação ao de outras categorias é quase o dobro.

Algumas hipóteses podem ser elencadas a despeito do resultado. Primeiro, os municípios recém-criados, apesar de terem se elevado à condição sem nenhum ônus financeiro - o que deverá mudar na nova legislação -, eles padecem pelo ineditismo na administração pública, e seus administradores podem incorrer em típicos vícios administrativos, semelhantes aos que se verificam em outros: corrupção, nepotismo, má gestão pública, descumprimento com os repasses constitucionais, etc. Segundo, encargos coma construção de infraestrutura, uma vez que o município recém-criado não conta com instalações apropriadas para o funcionamento da máquina administrativa. Terceiro, aquisiçãode equipamentos para o funcionamento da máquina administrativa. Quarto, gastos com recursos humanos, sobretudo nas áreas de saúde e educação, um dos maiores orçamentos que,inclusive, deve observar a Constituição Federal. Entre outros.

Os resultados da pesquisa também apontaram melhoria para a categoria dos municípios-mãe. A hipótese que se desenha é a mesma sustentada pelos políticos emancipacionistas, a de que os municípios remanescentes ganham com a redução dos gastoscom os distritos - aí entra o fator distância que reflete nos custos operacionais. A emancipação distrital conduz a outra racionalidade nos gastos públicos municipais.

Por isso, no decorrer da pesquisa, observou-se também a necessidade de ajustar o modelo agregando a variável "área municipal”, por estar implícito o fator distância entre asede municipal e a distrital.

Em suma, essa pesquisa tangenciou um tema que merece incluir outras variáveis categóricas. Não obstante a fragmentação territorial beneficiar, sobretudo, os municípios recém-criados em ganhos sociais incontestáveis, fato é que outras questões mereceriam maioratenção que a preocupação em criar municípios. Muitos municípios recém-criados, apesar demelhorarem seus indicadores sociais, ainda ostentam consideráveis taxas de analfabetismo,precariedade na assistência médica, na infraestrutura urbana e viária, etc. $\mathrm{O}$ governo federaldeveria criar mecanismos que promovessem a melhoria desses indicadores, em 
parceria comos estados e municípios, mesmo que isso incorra na fusão e incorporação de municípios, enão apenas na fragmentação territorial, expressa pelas emancipações distritais.

\section{REFERÊNCIAS}

BARACHO, Maria Amarante Pastor. Impactos da emancipação na arrecadação deICMS dos municípios. Revista do Legislativo, Belo Horizonte, p. 57-66. abr./set.2000.

BRASIL. Emenda Constitucional No 15 de 12 de setembro de 1996. Dá nova redação ao $\int 4^{\circ}$ do art. 18 da Constituição Federal. Brasília, 1996. Disponível em: <http://www.senado.gov.br/legislacao/const/con1988/CON1988_12.09.1996/art_18_.shtm >.Acesso em: 5 nov. 2013.

. Parecer no 1.141 de 2013. Redação final do Projeto de Lei do Senado nº 98, de $2002-$ Complementar ( $\mathrm{n}^{\circ}$ 416, de 2008 - Complementar, na Câmara dos Deputados). Brasília, 16 de outubro de 2013. Disponível em: $<$ http://www.senado.gov.br/atividade/materia/detalhes.asp?p_cod_mate=113088>.

Acessoem: 14 nov. 2013.

BREMAEKER, François E. J. de. Limites à criação de novos municípios: a Emenda Constitucional $n^{\circ}$ 15. Revista Brasileira de Administração Pública, Rio de Janeiro, v. 43, n.219, p. 118-128, abr./dez. 1996. Os novos municípios brasileiros. Revista Brasileira de Administração Pública, Rio de Janeiro, v. 38, n. 200, p. 82-92,.jul../set. 1991.

CARVALHO, Ailton Mota de. Viabilidade dos municípios mineiros. Belo Horizonte: IGA,1985.

CASTRO, Juliana. Com 5 novos municípios, Brasil agora tem 5.570 cidades. O Globo, 9 jan.2013. País. Disponível em: <http://oglobo.globo.com/pais/com-5-novos-municipiosbrasilagora-tem-5570-cidades-7235803>. Acesso em: 4 nov. 2013.

CRETELLA JR., José. Direito Administrativo Municipal: Evolução histórica do município. Rio de Janeiro: Forense, 1981, p. 31-47.

DILMA veta projeto que permitia criação de novos municípios no país. G1, política. Disponível em: <http://g1.globo.com/politica/noticia/2013/11/dilma-veta-projetoquepermitia-criacao-de-novos-municipios-no-pais.html>. Acesso em: 15 nov. 2013.

EMAMCIPAÇÃO - Líderes falam em fechamento de BR-364. Jornal Eletrônico Rondoniaovivo.com, 18 mar. 2013.2 Disponível em: <http://www.rondoniaovivo.com/noticias/emancipacao-lideres-falam-em-fechamentodebr-364/98792\#.UoTnu3CkrgU>. Acesso em: 14 nov. 2013.

GARCIA, Ricardo Alexandrino. Regressão logística. Belo Horizonte: UFMG, s.d. Apresentação (32 slides).

MESQUITA, Zilá. Emancipações no RS: alguns elementos para reflexão. Revistas Eletrônicas FEE, sd. Disponível em: 
<http://revistas.fee.tche.br/index.php/indicadores/article/viewFile/720/968>. Acesso em: 14 nov. 2013. 16

NÉRI, Felipe. Senado aprova projeto que permite a criação de novos municípios. G1, política. Disponível em: <http://g1.globo.com/politica/noticia/2013/10/senado-aprovaprojeto-quepermite-criacao-de-novos-municipios.html>. Acesso em: 5 nov. 2013.

NUNES, Marcos A. Estruturação e reestruturações territoriais da região do Jequitinhonhaem Minas Gerais. 2001. 2006f. Dissertação (Mestrado em Geografia e Organização Humanado Espaço), Universidade Federal de Minas Gerais, 2001.

PLENÁRIO aprova regras para a criação de municípios. Jornal do Senado, Senado Federal, 17 out. 2013. Disponível em:<http://www12.senado.gov.br/jornal/edicoes/2013/

10/17/plenario-aprova-regras-paracriacao-de-municipios>. Acesso em: 5 nov. 2013.

RÖCKERT, Aldomar Arnaldo. Emancipações distritais: notas de discussão. Boletim Gaúchode Geografia, Porto Alegre, n. 12, p. 49-53, maio 1984. Disponível em: <http://seer.ufrgs.br/index.php/bgg/article/view/37787/24375>. Acesso em: 14 nov. 2013.

SEN, Amartya. Desenvolvimento como liberdade. Tradução Laura Teixeira Motta. São Paulo: Companhia das Letras, 2010.

SENADO aprova projeto que pode criar até 188 novos municípios no país. Diário de Pernambuco.com.br. Disponível em:<http://www.diariodepernambuco.com.br/app/noticia/politica/2013/10/16/interna_poli tica,468433/senado-aprova-projeto-que-pode-criar-ate-188-novos-municipios-no-pais.shtml>. Acesso em 14 nov. 2013.

SOUTO, Isabella. Pressão por independência. JusBrasil. Disponível em: $<$ http://portalfederativo.jusbrasil.com.br/politica/6728154/pressao-por-independencia $>$. Acesso em: 14.nov. 2013.

SOUZA, Hilda Regina Silveira Albandes de. Primeiras reflexões sobre a Emenda Constitucional Federal n. 15 - criação, incorporação, fusão e desmembramentos de municípios. Revista Trimestral de Direito Público, São Paulo, n. 17, p. 208-219, 1997.

WERKEMA, M.C. C. \& AGUIAR, S. Análise de Regressão: como entender o relacionamento entre as Variáveis de um Processo. Belo Horizonte: Fundação Cristiano Ottoni/UFMG, 1996. 
ANEXO 1

Estados com mais distritos em condições de se emancipar

\begin{tabular}{|c|c|c|}
\hline Estado & $\begin{array}{l}\text { Distritos prontos para } \\
\text { se emanciparem }\end{array}$ & $\begin{array}{l}\mathrm{N}^{\circ} \text { atual de } \\
\text { municipios }\end{array}$ \\
\hline Maranhão & 32 & 217 \\
\hline Bahia & 28 & 417 \\
\hline Ceará & 26 & 184 \\
\hline Pará & 21 & 144 \\
\hline Pernambuco & 12 & 185 \\
\hline Mato Grosso & 11 & 141 \\
\hline Amazonas & 9 & 62 \\
\hline Goiás & 6 & 246 \\
\hline São Paulo & 6 & 645 \\
\hline Espírito Santo & 4 & 78 \\
\hline Rio Grande do Norte & 4 & 167 \\
\hline Rio de Janeiro & 4 & 92 \\
\hline Mato Grosso do Sul & 3 & 79 \\
\hline Minas Gerais & 3 & 853 \\
\hline Rondônia & 3 & 52 \\
\hline Sergipe & 3 & 75 \\
\hline Acre & 2 & 22 \\
\hline Paraíba & 2 & 223 \\
\hline Santa Catarina & 2 & 295 \\
\hline Amapá & 1 & 16 \\
\hline Paraná & 1 & 399 \\
\hline Roraima & 1 & 15 \\
\hline Tocantins & 1 & 139 \\
\hline TOTAL & 185 & \\
\hline
\end{tabular}

Fonte: Adaptado de: União Brasileira em Defesa da Criação de Novos Municípios (UBDCNM) e Instituto Brasileiro de Geografia e Estatística (IBGE). In: NÉRI, Felipe. MA, BA e CE podem liderar criação de novos municípios, diz estudo. G1, política.

Disponível em: <http://g1.globo.com/politica/noticia/2013/10/nova-lei-podegerarmais-municipios-em-ma-ba-e-ce-diz-levantamento.html>. Acesso em:

$$
12 \text { nov. } 2013 .
$$


ANEXO 2

Glossário dos termos da Lei

\section{CAPÍTULO I}

DISPOSIÇÕES PRELIMINARES

Art. $1^{\circ}$ Esta Lei Complementar dispõe sobre a criação, a incorporação, a fusão e o desmembramento de Municípios, nos termos do $\int 4^{\circ}$ do art. 18 da Constituição Federal.

Art. $2^{\circ}$ A criação, a incorporação, a fusão e o desmembramento de Municípios dependerão da realização de Estudos de Viabilidade Municipal (EVM) e de consulta prévia,mediante plebiscito, às populações dos Municípios envolvidos, e far-se-ão por lei estadual,obedecidos os prazos, procedimentos e condições estabelecidos nesta Lei Complementar.

Art. $3^{\circ}$ Para os efeitos desta Lei Complementar, considera-se:

I - criação: a emancipação de área integrante de 1 (um) ou mais Municípios preexistentes, preferencialmente distritos, originando um novo Município com personalidadejurídica própria;

II - incorporação: a completa integração de um Município a outro preexistente, perdendo o Município integrado sua personalidade jurídica, prevalecendo a do Município incorporador;

III - fusão: a completa integração de 2 (dois) ou mais Municípios preexistentes, originando um novo Município com personalidade jurídica própria;

IV - desmembramento: a separação de área de um Município preexistente para integrar-se a outro Município também preexistente, prevalecendo a personalidade jurídica doMunicípio a que se integrar; e

$\mathrm{V}$ - Municípios envolvidos: aqueles que sofrerem alteração em sua área geográfica decorrente de criação, incorporação, fusão ou desmembramento.

Fonte: BRASIL (2013). 


\section{ANEXO 3}

Etapas para a Criação de Municípios

1. Protocolar na Assembleia Legislativa pedido de criação do município assinado por pelo menos $20 \%$ dos eleitores do distrito, obedecendo às seguintes condições:

- Eleitorado igual ou superior a 50\% da população do distrito;

- Ter "núcleo urbano já constituído" e dotado de infraestrutura, edificações e equipamentos "compatíveis com a condição de município";

- Ter arrecadação superior à média de 10\% dos atuais municípios do estado;

- Área urbana não pode estar situada em reserva indígena, área de preservação ambiental ou área pertencente à União, a autarquia ou fundação do governo federal.

2. Após o pedido, elaboração em 180 dias, pela Assembleia Legislativa, de "estudo de viabilidade" do novo município e área remanescente do município do qual o distritopretende se separar. O estudo deverá verificar a viabilidade econômica, ambiental e política do novo município. Concluída essa etapa, o relatório terá de ser apreciado pelos deputados estaduais, que poderão arquivar ou aprovar o projeto.

3. Se o pedido for aprovado pela assembleia, será realizado um plebiscito que envolverá apopulação do distrito interessado em se emancipar e a do município ao qual o distrito pertence.

4. Se no plebiscito vencer a opção "sim", a assembleia legislativa terá de votar uma lei estadual autorizando a criação do novo município.

5. Após a aprovação da lei pela assembleia, será marcada data para eleição de prefeito, vice evereadores do novo município.

Fonte: Plenário (2013).

Nota: No sítio do Senado constam vários arquivos sobre a matéria (os trâmites). Cada a ocuparia inúmeras páginas neste trabalho. Por isso optou-se pelo resumo de matéria jornalística.Apesar de que não conste o número mínimo populacional para cada região brasileira, e o Art. 22 dalei, que se refere à indenização dos municípios remanescentes pelos recém-criados. 